\title{
Professional Autonomy and Progress of Occupational Therapy - A Case Study on a Neglected Health Profession in Malaysia
}

\author{
Siew Yim Loh ${ }^{*}$, Gail Boniface ${ }^{2}$, Lynette Mackenzie ${ }^{3}$, Lorie Richards ${ }^{4}$ \\ ${ }^{1}$ Department of Rehabilitation, University of Malaya, Kuala Lumpur, Malaysia \\ ${ }^{2}$ School of Healthcare Sciences Cardiff University Heath Park Cardiff, United Kingdom \\ ${ }^{3}$ Department of Occupational Therapy, The University of Sydney, Australia \\ ${ }^{4}$ Department of Occupational and Recreational Therapies, University of Utah, USA
}

*Corresponding author: Siew Yim Loh, Department of Rehabilitation, Faculty of Medicine, University of Malaya, Malaysia. Email: syloh@um.edu.my

Citation: Loh SY, Bonfice G, Mackenize L, Richards L (2017) Professional Autonomy and Progress of Occupational Therapy - A Case Study on a Neglected Health Profession in Malaysia. J Hosp Health Care Admin: JHHA-105. DOI: 10.29011/JHHA-105. 100005

Received Date: 07 September 2017; Accepted Date: 12 December 2017; Published Date: 20 December 2017

\begin{abstract}
Professional autonomy is positively related to professional involvement, job satisfaction, motivation and meta-cognitive learning processes in developing a profession and its workplace practice. It also affects the general well-being of individual professionals. Increased professional autonomy is associated with increased task variability and better customized patient-centered care. However, health profession in developing countries are often with violated role autonomy, hindering them from securing the full benefits of autonomy for its members, and impacting ability for future growth pathway for the profession. The aim of this paper is to present an analytical perspective of the current issues affecting the autonomy and progress of the Occupational Therapy profession in Malaysia. Three key concerns emerged. These were: - i) low numbers of occupational therapists in Malaysia, ii) low quality and lack of university-based education and iii) low professional autonomy experienced by Malaysian occupational therapists due to the dominance of the medical rehabilitation discipline. These issues affect the advancement of cost-effective, evidence-based, best practice for the consumers of rehabilitation in Malaysia who need occupational therapy clinical services. These issues have reduced the independence and interdisciplinary role of Malaysian occupational therapists in health and social care.
\end{abstract}

Keywords: Autonomy; Challenges; Health System; Medical Dominance; Medical Hagemony; Occupational Therapy; Role Autonomy; Social Care

\section{Introduction}

There is currently an increasing prevalence of noncommunicable chronic health conditions and the global population is ageing rapidly $[1,2]$. The effective management of chronic conditions and the needs of ageing people require much more than traditional medical approaches. People with chronic conditions often have significant levels of disabilities, which impact their participation in meaningful activities and societal roles. Occupational therapy can improve the health and quality of life of these people by facilitating participation in meaningful occupations [3-6]. Occupational therapy is particularly well-positioned to provide rehabilitation services that address the needs of the person, the activities and occupations they engage in to fulfil their roles, and the impact of their environments [7-8]. Many countries have proven the cost-effectiveness of occupational therapist-led services [9-11].

A university level preparation for practice can better prepare empowered health professionals, working within their profession's code of ethics [12]. Occupational therapists, like other health professionals, are educated to deliver personcentered-care, emphasizing evidence-based collaborative practices, quality improvement approaches, and informatics [13]. A truly collaborative team operates in a cooperative process where members are empowered to make their own informed evidence- 


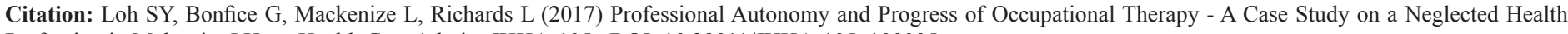
Profession in Malaysia. J Hosp Health Care Admin: JHHA-105. DOI: 10.29011/JHHA-105. 100005

based decisions in partnership [14]. In most developed countries, occupational therapists function autonomously in the intervention plan to ameliorate the participation barriers, and to enable occupational performance $[3,5]$. In these contexts, occupational therapy has a pivotal role in the organization of health care. Empirical studies have shown that professional autonomy is positively related to job involvement, satisfaction, and the motivation of professionals. Professional autonomy also contributes to the general health and well-being of professionals [15], which leads to better continuity of care for patients [16]. Occupational Therapists in developed countries enjoy greater autonomy and recognition as professionals [17], compared to developing countries [18-19]. In Malaysia, there has been a steep decline in the autonomy of occupational therapists over the last decade [20]. This has created a great disparity in the autonomy status between Malaysian occupational therapists and their counterparts practicing in developed countries, and contributing to the occupational stress and demoralization of the health professionals [21-22].

A common feature of less developed countries is the organisation of healthcare within an entrenched autocratic medical model, compared to a more autonomous model modelled by health services in more developed countries. Under such medical governance, occupational therapists often experience a lack of empowerment to implement occupational therapy interventions independently, develop new evidence-based programs or make decisions in collaboration with their patients - an experience which meets the definition of occupational injustice, which is the denial of rights to engage in occupations that meet the individual needs of occupational therapists and their capacity to develop their potential [23-24]. Malaysian occupational therapists also experience occupational-deprivation (being denied opportunities and resources to engage in high quality occupational therapy services), oppression (being marginalised and disempowered by a dominant medical rehabilitation profession), with potential job dissatisfaction and demoralisation in the workplace $[22,25]$. In the USA, the American Council on Occupational Therapy Education, an autonomous, independent body, sets the standards for what needs to be in Occupational Therapy curricula and what degrees can be accredited. Secondly, there is a national examination for certification following graduation from an accredited program that is required to be passed in order to practice occupational therapy. Thirdly, each state has a licensure system, whereby no occupational therapist can practice in that state without being licensed there and the licensure bill states what the therapist can do in that state. Lastly, a big determinant is what the payers (usually insurers) will pay for key significant services offered by occupational therapists. In brief, the governance of occupational therapy occurs at several levels and is determined by the occupational therapy profession and is supplemented by other stakeholders in healthcare. This has taken years to build up, but it has yet to begin in Malaysia.
Malaysian health care policy and educational policy need to acknowledge and facilitate occupational therapy autonomy and governance to provide the best standard of healthcare in Malaysia. However, in Malaysia, complex socio-cultural and political factors have compounded the lack of development of occupational therapy. This paper aims to present an analytical perspective of the current issues affecting the autonomy of occupational therapy and to highlight the issues hindering the development of occupational therapy in Malaysia.

\section{Method}

This discursive case study on the occupational therapy profession in Malaysia was conducted between, September 2015- July 2017. Three occupational therapy leaders who met the following criteria of i) being engaged in their country's professional association, ii) having participated in the World Federation of Occupational Therapists (WFOT), and iii) leading occupational therapy education in their countries were invited by the first author to reflect, review and discuss the potential issues affecting the profession's growth in Malaysia. A human resource survey of occupational therapists in a large medical hospital was also conducted. Using an analytical approach, the issues were discussed with reference to the home countries of the co-authors, and data from the World Federation of Occupational Therapists was used to inform the preliminary insights.

\section{Findings}

Three themes emerged from the discussions of core issues affecting the progress and autonomy of the occupational therapy profession in Malaysia. Electronic discussions were held between the primary author and each of the three co-authors and then a draft of the issues was debated leading to a consensus of three key themes which are further elaborated below.

\section{Theme 1: Low numbers of occupational therapists in Malaysia}

Malaysia only has a total of 1,395 occupational therapists to serve a population of 32 million. This compares with 16,000 occupational therapists in Australia for a population of 25 million, and 33,383 occupational therapists in the United Kingdom for a population of 65 million [26]. This translates to a ratio of only one Malaysian occupational therapist to 17,777 people, compared to 1:656 for Malaysian medical practitioners and 1:305 for Malaysian nurses [27]. Occupational therapists therefore have a tremendous challenge in being able to provide the necessary occupational therapy interventions to improve occupational participation and quality of life for Malaysians. Occupational therapists are underrepresented in key service areas (see Table 1), which will inevitably have a detrimental effect on cost-effective patient outcomes. In addition, in the 2015 fiscal year [28], Malaysia was classified as an 
Citation: Loh SY, Bonfice G, Mackenize L, Richards L (2017) Professional Autonomy and Progress of Occupational Therapy - A Case Study on a Neglected Health Profession in Malaysia. J Hosp Health Care Admin: JHHA-105. DOI: 10.29011/JHHA-105. 100005

upper middle-income economy (GNI between: $\$ 4,126$ to $\$ 12,745$ ). Despite this classification, Malaysia does not compare well to other countries in terms of the ratio of occupational therapists in relation to the general population (see Table 2).

\begin{tabular}{|c|c|c|c|}
\hline \multirow{2}{*}{ No } & \multirow{2}{*}{ AREA } & No of therapists in 2008 & No of therapists in 2014 \\
\cline { 3 - 4 } & & $\mathbf{( 2 5}$ million population) & (30 million population) \\
\hline 1 & Public hospitals & $38776 \%$ & $105075.2 \%$ \\
\hline 2 & Educational settings & $8016 \%$ & $956.9 \%$ \\
\hline 3 & Private settings & $40 \% \%$ & $25017.9 \%$ \\
\hline & TOTAL & $507100 \%$ & $1395100 \%$ \\
\hline
\end{tabular}

Table 1: Occupational therapists per practice setting in Malaysia, 2008 -2014 (MOH, 2016).

\begin{tabular}{|c|c|c|c|}
\hline Country & No of OT (Jan 2015) & Population (Jan 2015) & OT per 100,000 (Jan2015) \\
\hline Malaysia & 1500 & $30,187,896$ & 5 \\
\hline Sweden & 9000 & $9,631,261$ & 93 \\
\hline Canada & 9827 & $35,524,732$ & 27 \\
\hline United Kingdom & 36,043 & $63,489,234$ & 56 \\
\hline Japan & 47,759 & $126,999,808$ & 37 \\
\hline USA & 113,200 & $322,583,006$ & 35 \\
\hline
\end{tabular}

Table 2: Ratio of occupational therapists to population across sample countries.

\section{Theme 2: Low qualification of occupational therapy graduates}

The first author, based in Malaysia, presented the data on manpower in a large university-based hospital which employs the highest number of occupational therapists in Malaysia. Table 3 outlines the characteristics of this cohort of occupational therapists. The Malaysian occupational therapy profession is largely female dominated, (like many other countries), but most of these therapists were at the lowest, diploma level certification (unlike

many postgraduate-attained levels in the western countries). Table 4 below provides information about selected WFOT approved Occupational Therapy programs from different WFOT member countries, and most have several programs to meet the Occupational Therapy needs for their country. In Japan alone, there are 147 schools offering Occupational Therapy programs. In the USA, occupational therapy is one of the fastest growing professions in the health care sector [29], and since 2007 the minimum entry qualification for new graduates has to be at a Master degree or higher to be registered to work [30-31].

\begin{tabular}{|c|c|c|}
\hline Characteristic & $\mathbf{n}$ & $\mathbf{\%}$ \\
\hline Female & 136 & 77.7 \\
\hline Malay & 158 & 90.3 \\
\hline Work duration at UMMC of 1-3 years & 99 & 56.6 \\
\hline Highest qualification = Diploma & 124 & 70.9 \\
\hline Currently pursuing post graduate studies & 34 & 13.7 \\
\hline
\end{tabular}

Table 3: The background of therapists in University Malaya Medical Centre (Dec 2016) $n=175$.

\begin{tabular}{|c|c|c|c|}
\hline $\begin{array}{c}\text { Country out of } \\
97 \text { countries }\end{array}$ & $\begin{array}{c}\text { No of OT } \\
\text { programs }\end{array}$ & Level & $\begin{array}{c}\text { Total population } \\
2017\end{array}$ \\
\hline
\end{tabular}

\begin{tabular}{|c|c|c|c|}
\hline Canada & 15 & $\begin{array}{c}\text { Masters, } \\
\text { PhD }\end{array}$ & $36,286,378$ \\
\hline New Zealand & 2 & $\begin{array}{c}\text { Bachelors, } \\
\text { PhD }\end{array}$ & $4,604,871$ \\
\hline Sweden & 10 & $\begin{array}{c}\text { Bachelors, } \\
\text { Master, } \\
\text { PhD }\end{array}$ & $9,920,624$ \\
\hline UK & 59 & $\begin{array}{l}\text { Bachelors, } \\
\text { Master }\end{array}$ & $65,336,540$ \\
\hline USA & 160 & $\begin{array}{l}\text { Master, } \\
\text { PhD }\end{array}$ & $326,474,013$ \\
\hline India & 19 & $\begin{array}{c}\text { Bachelors, } \\
\text { Master }\end{array}$ & $\begin{array}{c}1,349,516,523(1.34 \\
\text { billion) }\end{array}$ \\
\hline Japan & 140 & $\begin{array}{c}\text { Bachelors, } \\
\text { Master }\end{array}$ & $126,323,715$ \\
\hline Malaysia & 3 & $\begin{array}{l}\text { Diploma, } \\
\text { Bachelors, }\end{array}$ & $31,025,632$ \\
\hline Australia & 17 & $\begin{array}{c}\text { Bachelors, } \\
\text { Master, } \\
\text { PhD }\end{array}$ & $24,641,662$ \\
\hline \multicolumn{4}{|c|}{ OT= Occupational therapy (Source: WFOT (2017) } \\
\hline
\end{tabular}

Table 4: Number of programs in selected WFOT member countries.

\section{Theme 3: Low professional autonomy}

A significant impact on the autonomy of the Malaysian Occupational Therapy profession, was the decision of the health ministry to reorganize and place Occupational Therapists under the governance of the medical rehabilitation physicians [20-22,32]. Since 2012, the autonomous leadership position for occupational therapy under the hospital director was challenged and removed, and placed under the direct governance of rehabilitation physicians, 


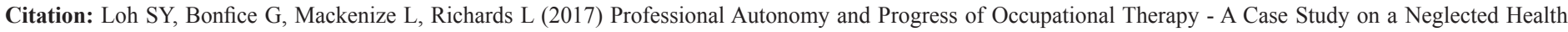
Profession in Malaysia. J Hosp Health Care Admin: JHHA-105. DOI: 10.29011/JHHA-105. 100005

which is reflective of historical practices in the USA [33-34]. Such governance makes it harder for occupational therapists to lobby for their increased autonomy as this would introduce a conflict-of-interest for medical rehabilitation physicians to support occupational therapy. Such a lack of autonomy may negatively influence potential Malaysian applicants to undertake occupational therapy education and enter the profession.

\section{Discussion}

This case study has identified three key issues that negatively affect the development of occupational therapy in Malaysia. The numbers of occupational therapists in Malaysia are a long way off the ideal ratio of therapists per

person in the Malaysian population. Approaching an ideal ratio will be difficult to achieve in the coming decades because of the lack of university-based undergraduate and postgraduate educational programs for Occupational Therapists in Malaysia. This issue is exacerbated by the decision of the Malaysian Ministry of Health decision to initiate more education programs for Rehabilitation Physicians which makes the difference in professional ratios even greater between occupational therapists and medical practitioners. Consequently, in several hospitals, experienced occupational therapists find themselves being supervised by newly graduated rehabilitation physicians. The low numbers of occupational therapists also mean that consumers do not have access to the specialised domains of occupational therapy expertise such as specific rehabilitation services, preventive health services, and primary care services.

The second theme relates to the lower entry qualification of occupational therapists. There is a great shortage of universitybased educational programs approved by the World Federation of Occupational Therapists to provide evidence based education to prepare occupational therapists to be the leaders in their field. The approval and management of educational programs for Occupational Therapy in Malaysia is still under the governance of the Ministry of Health, which, by merit, can only offer diplomastatus programs [20] or the equivalent to certificate level in the USA. In addition, most overseas-trained occupational therapists with a Master's Entry qualification are not recognized by the Ministry of Health, which makes it difficult for them to secure a post. This means that supplementing the occupational therapy workforce with overseas trained occupational therapists will not be an effective way forward. The University of Malaya, a premier university in Malaysia, offers no undergraduate bachelor program nor any postgraduate degree in occupational therapy, despite university education being recognized as essential to the professional education of occupational therapists [35].

The third theme relates to professional autonomy which refers to the right to use discretion and judgment within the scope of practice of a profession, or an individual's freedom to exercise professional judgment in practice activities -an important part of professional philosophy and theory [36]. There is evidence that in countries where Occupational Therapy is recognized as an autonomous profession, there are positive outcomes for people receiving occupational therapy [31]. The World Federation of Occupational Therapy's position statement clearly states the importance of the professional autonomy of Occupational Therapy [32] and the medical physician profession also claims professional autonomy is fundamental to high quality patient care [33]. However, the occupational therapy profession in Malaysia is clearly losing its professional autonomy status [34] and contributing to occupational pressure at work $[12,35]$.

The themes identified in this case study are interrelated. For example, low numbers of occupational therapists will make it very difficult for the profession to assert its autonomy. This is related to the rehabilitation medicine profession having occupational therapy placed under their jurisdiction within the health care system - continuing the struggle for autonomy [34]. Evidence shows that health professions have been restricted in their practice by medical dominance [33,35-37]. A lack of understanding of the roles of different health professionals, a lack of health policies to advance the field, and a restricted medical interpretation of the term 'rehabilitation' is currently working against true inter-disciplinary collaboration, which is viewed internationally as desirable for the best patient outcomes [38].

\section{Future Direction -Occupational Therapy Practice, Education and Research}

This analytical review of the occupational therapy discipline in Malaysia calls for more awareness of the professional roles, and direct representation at the policy making level. Occupational Therapy education at university-based setting should be recommended to replace the diploma level programs (vocational education) since education is fundamental to enable occupational therapists to function at a more autonomous and proactive level $[39,40]$. Klaiman [41] suggested that the autonomous role of occupational therapists is important as the profession continues to refine its body of practice and knowledge, with exciting opportunities in the future for advanced clinical and academic practice. As a global profession with more than 420,000 occupational therapists worldwide [42], future career prospects look very bright for Occupational Therapists in countries like Canada, USA and Australia. Significant contributions are being made by occupational therapists to public health, health promotion, curative and rehabilitation services, and community based services, locally and internationally. The medical physicians assert autonomy is important to patient care [43-44], but the irony is these physicians erodes the autonomy of health professionals and dominates other disciplines. There is an urgent need for Malaysian health care 
Citation: Loh SY, Bonfice G, Mackenize L, Richards L (2017) Professional Autonomy and Progress of Occupational Therapy - A Case Study on a Neglected Health Profession in Malaysia. J Hosp Health Care Admin: JHHA-105. DOI: 10.29011/JHHA-105. 100005

policy makers to become aware of and recognize the independent and unique contribution of the Occupational Therapy discipline, with clear evidence of health improvement outcomes [45]. Indeed, opportunities exist for Occupational Therapists to promote their roles and the services that can be provided that extend beyond traditional rehabilitation to encompass curative, preventive and community-based services. Therefore, the empowerment of Occupational Therapists in Malaysia consistent with the WFOT position statement on the autonomy of Occupational Therapy should be honoured by Malaysian governing bodies, so that the profession can be supported to advance occupational therapy practices, and Malaysians can benefit from the cost-effective services that Occupational Therapists can offer.

\section{Conclusion}

The analytical discussion of key professional issues for occupational therapy in Malaysia uncovered three themes (low numbers, low quality-education and low autonomy) which created many disadvantages for occupational therapy development in Malaysia compared to other WFOT member countries. The lack of awareness of Occupational Therapy as a profession and its roles in the field of health-care in Malaysia will continues to be prolonged due to a serious lack of numbers, a debilitating lack of quality education preparation, and most importantly, an erosion of professional autonomy of occupational therapy -coupled with, a lack of recognition of the role of occupational therapy particularly in rehabilitation settings, and a lack of WFOT-approved programs. All these factors will stagnate the progress of the profession. This calls for concerted efforts by the profession, the Ministry of Health and healthcare administrators to seriously address the i) lack of recognition of Occupational Therapy as a profession, ii) the lack of university-based, WFOT approved training programs, which have hindered the full development of occupational therapy and the iii) loss of professional autonomy which silenced its contribution to health and social care in Malaysia. Every profession should ensure their role autonomy is protected, in order to reap the full benefits of autonomy for its members, to enhance a future vision and pathway for the profession, and to ensure the ongoing development of the profession. Strategies to address the disempowerment of occupational therapy need to be developed and addressed locally, and internationally.

\section{Acknowledgement}

Ritchard Ledgerd MSc. WFOT Human Resources Project. World Federation of Occupational therapy.

\section{References}

1. Jemal A, Murray T, Ward E, Samuels A, Tiwari RC, et al. (2005) Cancer statistics, 2005. CA Cancer Clin 55: 10-30.
2. Dexter PR, Miller DK, Clark DO, Weiner M, Harris LE, et al. (2010) Preparing for an Aging Population and Improving Chronic Disease Management. AMIA Annual: 162-166.

3. Pizzi MA, Richards LG (2017) Promoting Health, Well-Being, and Quality of Life in Occupational Therapy: A Commitment to a Paradigm Shift for the Next 100 Years Am J Occup Ther.

4. Loh SY, Jonsson H (2016) Cancer Survivorship Care: A perspective from an Occupational-Participation Approach. J Cancer Sci Ther 8.

5. Hildenbrand WC, Lamb AJ (2013) Occupational therapy in prevention and wellness: retaining relevance in a new health care world. Am J Occup Ther 67: 266-71.

6. Foste, ER., Bedekar M, Tickle-Degnen, L. (2014) Systematic Review of the Effectiveness of Occupational Therapy-Related Interventions for People with Parkinson's Disease. The American Journal of Occupational Therapy 68: 39-49.

7. Cramm H (2009) The person environment occupation circle tool: A simple way to bridge theory into practice. OT Now.

8. Law M, Cooper B, Susan S, Steward D, Rigby, et al. (1996) The person-environment Occupational Model: A transactive approach to occupational performance. Canadian Journal of Occupational therapy 63.

9. Rexe K, Lammi MB, von Zweck C (2013) Occupational therapy: Costeffective solutions for changing health system needs. Healthcare Quarterly.

10. Brindle D (2015) 'Punching above their weight': the impact of occupational therapists. Guardian.

11. Nagayama H, Tomori K, Ohno K, Takahashi K, Ogahara K, et al. (2016) Effectiveness and Cost-Effectiveness of Occupation-Based Occupational Therapy Using the Aid for Decision Making in Occupation Choice (ADOC) for Older Residents: Pilot Cluster Randomized Controlled Trial.

12. Kasher, A. (2005) Professional ethics and collective professional autonomy: A conceptual analysis. Ethical perspectives: Journal of the European Ethics Network 11: 67-98.

13. Greiner AC, Knebel E (2003) Health Professions Education: A Bridge to Quality. Institute of Medicine (US) Committee on the Health Professions Education Summit. Washington (DC): National Academies Press (US)

14. Lavis J, Davies H, Oxman A, Denis JL, Golden-Biddle K, et al. (2005) systematic reviews that inform health care management and policymaking J Health Serv Res Policy: 35-48.

15. Lin BYJ, Lin YK, CC Lin, TT Lin (2013) Job autonomy, its predispositions and its relation to work outcomes in community health centers in Taiwan. Health Promot Int 28: 166-177.

16. Anand G, Chhajed D, Delfin L (2012) Job autonomy, trust in leadership, and continuous improvement: An empirical study in health care. Operations Management Research 5: 70-80.

17. Davis GL, Bordieri JE (1988) Perceived autonomy and job satisfaction in occupational therapists. American Journal of Occupational Therapy 42: 591-595.

18. Shi, Y., Howe, T. H. (2016) A Survey of Occupational Therapy Practice in Beijing, China. Occupational Therapy International 23: 186-195. 
Citation: Loh SY, Bonfice G, Mackenize L, Richards L (2017) Professional Autonomy and Progress of Occupational Therapy - A Case Study on a Neglected Health Profession in Malaysia. J Hosp Health Care Admin: JHHA-105. DOI: 10.29011/JHHA-105. 100005

19. Abu Tariah HS, Hamed RT, AlHeresh RA, Abu-Dahab SM, AL-Oraibi S (2011) Factors influencing job satisfaction among Jordanian occupational therapists: a qualitative study Aust Occup Ther J 58:405-11.

20. SY Loh (2012) Occupational Therapy in Malaysia. 4S2.4 Oral presentation for the 2012 Hong Kong International Occupational therapy conference.

21. SY LOH, Quek KF (2013) Moderators of occupational pressure in female health professionals-Individual differences and coping skills. Health 5.

22. SY LOH, Than W, Quek KF (2011) Occupational pressure-targeting organisational factors to ameliorate occupational dysfunction. J Occup Rehabil 21:493-500.

23. Durocher E, Gibson B, Rappolt S (2014) Occupational Justice: A Conceptual Review. Journal of Occupational Science 21: 418-430.

24. Wolf L, Ripat J, Davis E, Becker P, MacSwiggan J (2010) Theory meets practice: Applying an occupational justice framework. OT Now.

25. Pierce D (2009) Co occupation: The challenges of defining concepts original to occupational science. Journal of Occupational Science16: 203-207.

26. WFOT (2015) Human resources project.

27. Ministry of Health Malaysia (2016) KKM HEALTH FACTS 2016 FRONT.

28. Worldbank

29. US News (2014) The 20 Fastest-Growing Jobs.

30. Brown T, Crabtree JL, Wells J Mu K (2016) The entry-level occupational therapy clinical doctorate: The next education wave of change in Canada? Canadian Journal of Occupational Therapy 83: 306-316.

31. ACOTE (Accreditation Council for Occupational Therapy Education) (2015) ACOTE's statement on the entry-level degree for the OT and OTA.

32. Ministry of Health Malaysia (2005) Malaysia's health 2005 - Rehabilitation Medicine in Malaysia.
33. Ovretveit (1985) Medical dominance and the development of professional autonomy in physical therapy. Soc Health IIIness7:76-93.

34. Colman W (1992) Maintaining Autonomy: The Struggle Between Occupational Therapy and Physical Medicine. The American Journal of Occupational therapy.

35. Kenny D, Adamson B (1992) Medicine and the health professions: issues of dominance, autonomy and authority. Aust Health Rev 15: 319-334.

36. Roemer M, McKinlay HB, Arches J (1986) Proletarianization of physicians, organization of health services? Int J Health Serv 16: 469-471.

37. Krause EA (1996) Death of the Guilds: Profession, State and the Advance of Capitalism; 1930 to Present. New Haven, Conn: Yale University Press.

38. Atwal A, Caldwell K, (2002) Do multidisciplinary integrated care pathways improve interprofessional collaboration. Scandinavia Journal of caring science.

39. Esdaile SA, Roth LM (2000) Education not training: the challenge of developing professional autonomy. Occupational therapy International 7: $147-152$

40. WFOT (2009) World federation of occupational therapy 's position statement on professional autonomy.

41. Klaiman D (2006) Through the Looking Glass: Occupational Therapy in the Future. Occupational therapy now 8: 5-7.

42. WFOT Human resources project.

43. Wilson Physician Autonomy Essential to Patient Care.

44. Mastekaasa A (2011) How important is Autonomy to Professional Workers? Professions \& Professionalism 1: 36-51.

45. Rogers AT, Bai G, Lavin RA, Anderson GF (2016) Higher Hospital Spending on Occupational Therapy Is Associated with Lower Readmission Rates. 